\title{
CITRAAN PUISI ANAK MAJALAH BOBO EDISI 40-45 TAHUN 2016
}

\section{CHILD POEMS IN BOBO MAGAZINES 40-45 EDITION 2016 YEARS}

\author{
Fadhilatun Hayatunnufus \\ Kantor Bahasa Provinsi Lampung \\ Jalan Beringin II no. 40 Kompleks Gubernuran Telukbetung, Bandarlampung \\ Telepon (0721) 486408, Faksimile (0721) 486407 \\ Pos-el: dilanufus01@gmail.com
}

\begin{abstract}
Abstrak
Penelitian ini berjudul "Citraan Puisi Anak Majalah Bobo Edisi 40-45 Tahun 2016". Rumusan masalah dalam penelitian ini adalah citraan apa saja yang terdapat dalam puisi anak yang dipublikasikan dalam majalah Bobo. Tujuan penelitian ini adalah untuk mendeskripsikan citraan apa saja yang terdapat dalam puisi anak dalam majalah Bobo. Jenis penelitian ini adalah penelitian kualitatif. Teknik pengumpulan data yang digunakan adalah teknik studi pustaka. Pengolahan data penelitian dengan metode deskriptif analitik yang dilakukan dengan mendeskripsikan fakta-fakta dan menganalisisnya. Hasil penelitian ini menunjukkan bahwa citraan yang terdapat dalam puisi anak pada majalah Bobo Edisi 40-45 adalah citraan penglihatan, gerak, penciuman, pencecapan, dan perabaan. Citraan yang paling dominan digunakan oleh anak dalam membuat puisi pada majalah Bobo Edisi 40-45 adalah citraan penglihatan.
\end{abstract}

Kata kunci: sastra anak, puisi, citraan

\begin{abstract}
This research entitled "Child Poems in Bobo Magazines 40-45 Edition 2016 Years." The formulation of the problem in this study is what types of imagery contained in the poetry of children published in Bobo magazine. The purpose of this study is to describe any kinds of imagery contained in the poetry of children in Bobo magazine. The type of this research is a qualitative research. The technique which was used in data collection is a literature study from 15 poems. To analyse the data, the researcher used a descriptive analytic method which is done by describing facts and analyzing it. The results of this study indicate that the imagery contained in the poetry of children in Bobo magazine in 40-45 edition is visual imagery, kinestethic imagery, smell imagery, taste imagery, and tactile imagery. The most dominant image used by children in making poetry in Bobo magazine in 40-45 edition is visual imagery.
\end{abstract}

Keywords: literature child, poetry, imagery

\section{Pendahuluan}

Sastra anak adalah suatu karya sastra yang bahasa dan isinya sesuai dengan perkembangan usia, mencerminkan corak kehidupan, dan kepribadian anak, ditulis oleh anak, remaja, atau orang dewasa, baik lisan ataupun tertulis. Karya sastra tersebut berbentuk puisi, prosa, dan drama. Sastra anak memiliki kontribusi yang besar bagi perkembangan kepribadian anak dalam proses menuju kedewasaan. Melalui karya sastra penulis dapat mengungkapkan perasaan yang tersurat lewat pesan yang terkandung di dalamnya. Menurut Sarumpaet (2010:2), sastra anak adalah sastra terbaik yang mereka baca dengan karakteristik berbagai ragam, tema, dan format. Nurgiyantoro (2005:6) mengatakan bahwa sastra anak adalah sastra yang secara emosional psikologis dapat ditanggapi dan dipahami oleh anak dan pada umumnya berangkat dari fakta yang konkret dan mudah dipahami oleh anak-anak. Oleh 
karena itu, apa yang disebut dengan sastra anak tentu mengacu kepada kehidupan cerita yang berkolerasi dengan dunia anak-anak dan bahasa yang digunakan sesuai dengan perkembangan intelektual dan emosional anak. Saat ini puisi tidak hanya ditulis oleh kalangan dewasa, tetapi juga dari kalangan anak-anak. Puisi juga menjadi salah satu karya sastra yang diminati anak karena anak dapat menuangkan hasil pikiran dan perasaan yang sedang dirasakan dalam puisi tersebut. Puisi yang dibuat oleh anak-anak tentunya harus memperhatikan bunyi, pemilihan kata yang tepat, dan penggunaan citraan walaupun kemudian dimaklumi bahwa bentuk puisi anak biasanya sangat sederhana. Winarni (2014:9) mengatakan bahwa salah satu ciri puisi anak dibuat oleh anak-anak sesuai dengan kelompok usia anak, pada anak usia Sekolah Dasar menyukai puisi yang membicarakan kehidupan sehari-hari, petualangan, kehidupan keluarga yang nyata, dan kesesuaian dengan lingkungan sekitar tempat anak berada. Misalnya, anak yang yang berada di lingkungan sekitar pantai akan bersemangat jika puisi yang diberikan untuk dipelajari adalah puisi yang berbicara tentang pantai. Puisi anak-anak ataupun puisi dewasa memiliki struktur fisik puisi. Menurut Waluyo (1991:27) struktur fisik puisi terdiri atas barisbaris puisi yang bersama-sama membangun bait-bait puisi. Adapun unsur-unsur yang ada dalam struktur fisik puisi yaitu diksi, pencitraan (imaji), kata konkret, bahasa figuratif (majas), verifikasi, dan tipografi puisi. Perhatian terhadap unsur-unsur tersebut bukan bermaksud mempersulit cara penulisan puisi pada anak-anak. Akan tetapi, dengan memperhatikan unsur-unsur tersebut justru akan membantu anak untuk menonjolkan ungkapan perasaannya melalui puisi.

Dalam penelitian ini penulis bermaksud untuk melakukan kajian terhadap salah satu unsur fisik puisi, yaitu citraan. Citraan dapat juga dikatakan pengimajian. Citraan (imaji) adalah gambaran-gambaran angan dalam sebuah bahasa pada suatu karya. Waluyo (1991:78) mengatakan bahwa pengimajian adalah kata atau susunan kata yang dapat mengungkapkan pengalaman sensoris, seperti penglihatan, pendengaran, dan perasaan. Nurgiyantoro (2005:346) mengungkapkan bahwa penggunaan citraan dalam puisi dan teks kesusastraan secara umum berkaitan dengan tujuan memberikan gambaran secara konkret walaupun tetap hanya secara imajinatif kepada pembacanya. Berbicara mengenai imajeri sebuah puisi berarti kita berbicara mengenai imaji-imaji pancaindera langsung, seperti penglihatan, bunyi, sentuhan, bau, atau rasa (Tarigan, 2011: 136).

Pradopo (2008:81) menyebutkan jenis citraan terdiri atas (1) citraan penglihatan (visualimagery), yakni citraan yang memberi rangsangankepada indera penglihatan, hingga sering hal-hal yang tak terlihat jadi seolah-olah terlihat; (2) citraan pendengaran (auditory imagery), yakni citraan yang ditimbulkan oleh indera pendengaran (telinga) sehingga pembaca seolah-olah mendengarkan suara seperti yang digambarkan oleh penyair; (3) citraan perabaan (tactilimagery), yakni citraan yang melibatkan indera peraba (kulit) dan citraan ini menguraikan kata atau ungkapan yang terdapat dalam puisi dan seolah-olah dapat dirasakan, disentuh, atau diraba; (4)citraan penciuman (smell imagery), yakni citraan yang melukiskan atau menggambarkan lewat rangsangan yang seolah-olah dapat ditangkap oleh indera penciuman; (5) citraan pengecapan, yakni citraan yang melibatkan indera pengecapan (lidah) dan melalui citraan ini seolah-olah pembaca dapat merasakan sesuatu yang pahit, asam, asin, manis dan lainlain; dan (6) citraan gerak (kinaesthetic imagery), yakni citraan yang menggambarkan sesuatu yang sesungguhnya tidak bergerak, tetapi dilukiskan sebagai sesuatu yang dapat bergerak. Melalui berbagai citraan tersebut pembaca dapat memperoleh gambaran yang jelas mengenai pikiran dan perasaan yang diungkapkan oleh sang penyair.

Citraan yang akan dianalisis dalam penelitian ini adalah citraan yang terdapat pada puisi anak dalam majalah Bobo edisi 40 s.d. 45 penulis mengumpulkan data dengan mengikuti perkembangan terbaru dari majalah Bobo. Majalah Bobo merupakan majalah anak tertua yang terbit di Indonesia sejak tahun 1973 dan sampai sekarang masih diminati oleh 
berbagai pihak salah, khususnya anak-anak. Keragaman rubrik yang khusus diterbitkan untuk anak-anak menjadi salah satu alasan anak-anak tertarik membaca majalah tersebut. Salah satu rubriknya adalah puisi yang ditulis oleh anak-anak. Majalah Bobo memiliki Slogan "Teman Bermain dan Belajar" yang bertujuan untuk memberi pendidikan melalui bacaan yang seru untuk dibaca oleh anak-anak sembari diajak bermain. Hal tersebut menjadi alasan penulis dalam memilih majalah Bobo sebagai sumber data penelitian. Oleh sebab itu, peneliti tertarik untuk melakukan analisis terhadap puisi anak dalam majalah Bobo. Penelitian ini diberi judul "Citraan Puisi AnakMajalah Bobo Edisi 40-45".Sebagai bahan rujukan, penulis menggunakan bukubuku yang relevan sebagai panduan, yaitu buku-buku tentang sastra anak, puisi anak, stilistika sastra, dan sumber bacaan lainnya dari internet, jurnal, hasil penelitian, dan lainlain yang relevan dengan masalah tentang citraan dalam puisi. Salah satu hasil penelitian yang penulis ambil sebagai bahan rujukan adalah hasil penelitian Iswani Husna tentang "Analisis Citraan Puisi Anak dalam Majalah Bobo". Sumber penelitian ini penulis peroleh dari internet.

\section{Metode}

Metode yang digunakan dalam penelitian ini adalah metode deskriptif analitik yang dilakukan dengan cara mendeskripsikan faktafakta kemudian disusul dengan analisis (Ratna, 2004:53). Deskriptif analitik ialah suatu penelitian yang bertujuan untuk memberikan gambaran tentang realitas pada objek yang diteliti secara objektif. Sumber data dalam penelitian ini adalah majalah Bobo terbitan tahun 2016. Setiap edisi diterbitkan tiga puisi anak. Peneliti mengambil lima edisi sebagai sumber penelitian dan lima belas puisi yang terdapat didalamnya sebagai data penelitian.

Adapun langkah-langkah yang ditempuh dalam penganalisisan data dalam penelitian ini adalah sebagai berikut.

1. Membaca keseluruhan puisi yang terdapat dalam majalah Bobo edisi 40 S.D 45 pengidentifikasi baris puisi yang mengandung citraan.
2. Mencatat setiap baris puisi yang mengandung konsep kajian citraan.

3. Menentukan unsur citraan pada baris-baris puisi yang telah diidentifikasi.

4. Mengklasifikasi citraan yang terdapat dalam puisi anak majalah Bobo edisi 40 s.d.45.

5. Menganalisis citraan yang terdapat dalam puisi anak majalah Bobo edisi 40 s.d. 45.

6. Membuat simpulan.

\section{Pembahasan}

Sebagaimana dikemukaan dalam pendahuluan, teks puisi yang diteliti berasal dari majalah Bobo edisi 40-45yang berjumlah 15 puisi. Unsur-unsur citraan puisi anak dalam majalah Bobo edisi 40-45 yang akan dikaji dalam penelitian ini meliputi citraan penglihatan, pendengaran, perabaan, penciuman, pengecapan, dan gerak. Adapun judul puisi anak tersebut yakni, Taman Bunga karya Fadilah Rahmayani, Melatiku karya Syarifah Mufidah Wafa, Burung Berbulu Putih karya Najla Desva, Bundaku karya Angela Eva Alvariani, Pelangi karya Regina Hanna Berliana, Tas Baru karya Almira Lintang Nugraheni, Bunga Mawar Merah karya Rayhan Nur Abian, Paru-paru Dunia karya Ayesha Zhafira, Balerina karya Sofyana, Indah Negeri Ini karya Iska Agni Nanda, Matahari karya Luma, Air karya Yasmin, Jam karya Zahra Anita, dan Ibu karya Ummu Salimah. Puisi-puisi tersebut dibuat oleh anakanak usia sekolah dasar, mereka menulis puisi tersebut berdasarkan pengalaman atau apa yang mereka lihat. Pada usia anak-anak sekolah dasar, karya sastra yang paling menarik untuk mereka buat adalah puisi, mereka dapat memadukan kata-kata sehingga menimbulkan bunyi yang padu jika kita membacanya. Berikut ini adalah hasil analisis puisi anakkaryaFadilahRahmayani dalammajalah Bobo.

\section{TAMAN BUNGA}

Bila kutatap engkau

Hatiku sangat senang

Rupamu cantik

Warnamu menarik

Oh taman bungaku 
Bersemilah sepanjang waktu

Jangan pernah layu

Jangan lupa berkembang

Oh angin

Jangan kau sapu taman bungaku

Biarkan ia mekar

Menebar harum

Dalam puisi tersebut berisi tentang keindahan sebuah taman bunga. Citraan yang terlihat dalam puisi 'Taman Bunga" adalah citraan penglihatan, gerak, dan penciuman. Pada kalimat "Bila kutatap engkau" memberikan kesan kepada pembaca untuk ikut melihat sebuah taman bunga. Citraan gerak dapat tergambar pada baris "Oh angin/ Jangan kau sapu taman bungaku”. Kesan yang didapat oleh pembaca dalam baris tersebut adalah si penyair tidak ingin taman bunganya gugur karena tertiup angin kencang. Gambaran tentang bunga-bunga yang menebar harum merupakan unsur citraan penciuman yang terdapat dalam baris terakhir puisi tersebut yang berbunyi " Biarkan ia mekar/ menebar harum".

\section{MELATIKU}

SyarifahMufidah Wafa

Melatiku

Setiap hari kau kusiram pagi dan sore

Supaya kau selalu sehat

Dan aku ingin kau merekah indah

Melatiku

Aku menyayangi dan merawatmu selalu

Supaya kau tidak layu

Walau kupu-kupu menghisap madumu

Walau ulat memakan daunmu

Kau tetap cantik dan harum

Citraan yang terdapat dalam puisi "Melatiku" sangat mendukung arti atau kesan yang yang terdapat dapat puisi tersebut. Puisi tersebut memiliki citraan gerak dan pengecapan. Citraan gerak terlihat jelas pada kalimat "Setiap hari kau kusiram pagi dan sore". Pembaca dapat membayangkan bahwa setiap sore pengarang selalu menyiram bunganya. Citraan pengecapan terlihat jelas pada kata menghisap dan memakan pada bait terakhir puisi. Citraan penciuman telihat pada baris puisi yang berbunyi "Kau tetap cantik dan harum".

Gramatika, Volume VI, Nomor 1, Januari-Juni 2018

\section{RUMAHKU}

Rumahku

Betapa indahnya dirimu

Jika hujan turun

Engkau melindungiku

Jika matahari panas

Kau juga melindungiku

Terima kasih rumah

Engkau yang menyelamatkanku

Aku bias tinggal bersamamu

Sampai kapan pun

Dalam puisi tersebut berisi tentang rumah yang indah. Gambaran-gambaran tentang rumahnya pun terlihat jelas dalam puisi tersebut. Unsur citraan yang terdapat dalam puisi "Rumahku" adalah citraan penglihatan dan perabaan. Citraan penglihatan terdapat pada baris puisi yang berbunyi "Betapa indahnya dirimu", citraan perabaan tergambar pada kalimat "Jika hujan turun/ engkau melindungiku dan Jika matahari panas/ engkau juga melindungiku". Dalam kalimat-kalimat tersebut pembaca seolah merasakan cuaca dingin karena hujan dan panasnya sinar matahari.

\section{BURUNG BERBULU PUTIH}

Najla Desvaa

\section{Bertengger di atas pohon}

Bulu putih berparuh dan berkaki merah

Tatapan matanya begitu menggemaskan

Membuatku ingin menatapnya

Sayangnya,

Itu hanya angan-angan

Kau hanyalah lukisan

Yang ada dihadapanku

Tertipu semua orang melihatmu

Dan mulai berangan

Bahwa kau benar-benar ada

Tepat dihadapan mereka

Penyair menggunakan kata menatap (tatapan) untuk memunculkan sebuah citraan. Melalui kata menatap (tatapan) dapat dirasakan bahwa citraan yang terdapat dalam puisi tersebut adalah citraan penglihatan. Pembaca seolah-olah ikut melihat apa yang dilihat oleh pengarang.Hal tersebut tampak pada bait-bait puisi "Burung Berbulu Putih". 
Dari bait pertama sampai terakhir hanya terdapat citraan penglihatan.

PELANGI

Regina Hanna Berliana

Pelangi ada di langit

Indah sekali

Pelangi warna-warni

Sesudah hujan pelangi muncul

Pelanginya indah sekali

Banyak warnanya

Tuhan menciptakan pelangi

Terima kasih Tuhan

Dalam puisi berisi tentang menyampaikan tentang keindahan pelangi ciptaan Tuhan. Hanya terdapat citraan penglihatan dalam puisi tersebut. Bait pertama dan kedua puisi "Pelangi" tampak jelas digambarkan dengan menggunakan citraan penglihatan, seperti pada baris puisi yang berbunyi " Pelangi ada di langit/ indah sekali/ pelangi warna warni/ sesudah hujan pelangi muncul". Citraan penglihatan adalah citraan yang memberikan rangsangan kepada indera penglihatan, sehingga sering hal-hal yang tak terlihat jadi seolah-olah terlihat. Dari baris puisi tersebut, pembaca seolah-olah melihat pelangi yang berwarna-warni muncul setelah hujan.

\section{BUNDAKU}

Angela Eva Alvariani

Kau adalah wanita mulia

Orang yang pantang menyerah

Kau telah melahirkan kami

Bertaruh nyawa untuk kami

Kau selalu bercahaya di mata kami

Seperti bintang di malam hari

Seperti matahari di pagi hari

Seperti pelangi warna-warni

Kau begitu mulia

Surga pun ada di bawah kakimu

Terima kasih bunda

Dalam puisi "Bundaku" brisi tentang rasa terima kasih kepada orang tua yang telah melahirkan dan merawatnya. Unsur citraan yang didapat oleh pembaca adalah citraan penglihatan. Kata bercahaya seolah-olah menggambarkan kebahagian yang pengarang peroleh apabila melihat tokoh bunda dalam puisi tersebut. Pembaca juga dipancing untuk memberikan rangsangan kepada indera penglihatannya agar membayangkan tokoh bunda yang seolah-olah dapat dilihat seperti bintang atau matahari, seperti yang terdapat pada bait kedua puisi tersebut.

\section{TAS BARU}

Almira Lintang Nugraheni

Senangnya hatiku

Di hari Minggu

Ayah membelikan tas baru

Tas roda warna biru

Gambar frozen kesukaanku

Sekarang aku tidak berat lagi

Membawa buku sesuka hati

Aku akan rawat tas ini

Terima kasih ayah

Puisi "Tas Baru" berisi tentang perasaan senang pengarang karena dibelikan tas yang ia sukai. Unsur citraan yang terdapat dalam puisi tersebut adalah citraan penglihatan. Pada bait pertama terdapat kalimat yang berbunyi "ayah membelikan tas baru/ tas roda warna biru/ gambar frozen kesukaanku. Kalimat tersebut membuat pembaca berandai-andai ikut melihat sebuah tas baru bergambar frozen. Citraan penglihatan digunakan oleh pengarang untuk memberikan kesan pada puisi yang ditulisnya kemudian dapat dibayangkan oleh pembaca.

\section{BUNGA MAWAR MERAH}

Rayhan Nur Abian

Bunga mawar kau ditanam

Setiap hari kusiram

Agar subur dan berbunga

Bungamu silih berganti

Menghiasi tamanku

Bunga mawar kau indah

Warnamu merah merekah

Walau kau berduri tajam

tapi kau harum sepanjang hari

Puisi karangan Rayhan Nur Abian ini mengisahkan tentang keindahan bunga mawar merah yang selalu dirawatnya. Untuk memberikan kesan pada puisi yang ditulisnya, pengarang menggunakan citraan penglihatan dan penciuman. Citraan penglihatan digunakan agar pembaca seolah-olah ikut 
melihat keindahan bunga mawar. Hal ini tampak pada bait puisi yang berbunyi "Bungamu silih berganti/ menghiasi tamanku/ bunga mawar kau indah. Citraan penciuman terdapat dalam baris puisi yang berbunyi "walau kau berduri tajam/ tapi kau harum sepanjang hari/, dengan adanya citraan penciuman, pengarang mengajak seolah-olah pembaca ikut mencium harum bunga mawar merah.

\section{PARU-PARU DUNIA}

Ayesha Zhafira Maulana

Batangmu tinggi menjulang

Kayumu bisa dijadikan perabot rumah tangga

Meja, kursi, kusen, dan semuanya berasal darimu

Daunmu bisa menyaring udara

Terbayang jika dirimu tiada

Wahai pohon

Sekarang banyak penebangan liar

Dan pembakaran hutan

Pohon

Kaulah paru-paru dunia

Sebab jika dirimu tiada

Kami mungkin tak bisa bernafas dengan nyaman

Puisi "Paru-paru Dunia" karya Ayesha, mengisahkan tentang manfaat sebuah pohon dan kerugiannya jika tidak ada pohon. Unsur citraan yang digunakan pengarang dalam puisinya ini adalah citraan penglihatan dan gerak. Citraan penglihatan tampak pada baris puisi yang berbunyi "wahai pohon". Pengarang memberikan kesan bahwa pembaca seolah-olah melihat sebuah pohon. Citraan gerak terdapat pada baris yang berbunyi "Daunmu bisa menyaring udara", kata menyaring termasuk kelas kata kerja, proses melakukan sebuah pekerjaan. Oleh karena itu, kata menyaring dalam baris tersebut termasuk citraan gerak.

\section{BALERINA}

Sofyana Il-Liyin

Berputar mengitari panggung

Bagai burung merak

Meliukkan tubuh dengan indah

Bagai sang lumba-lumba beraksi

Meloncat ke sana ke mari

Bergerak dengan serasi

Dengan senyum tetap tersungging
Membuat betah penonton

Oh balerina-balerina sejati

Menari balet dengan lincah

Pasti sangat tekun berlatih

Mengasah diri menjadi terampil

Pengarang puisi "Balerina" bermaksud menyampaikan sosok balerina yang menari dengan lincah. Pengarang menggunakan citraan gerak dan penglihatan untuk memberikan kesan pada puisi yang ia buat. Citraan penglihatan digunakan oleh pengarang untuk memberikan kesan seolah-olah pembaca ikut menyaksikan pertunjukan balerina. Hal ini tampak pada bait ketiga puisi tersebut yang berbunyi "Oh balerina-balerina sejati/ Menari balet dengan lincah/ Pasti sangat tekun berlatih/ Mengasah diri menjadi terampil/". Citraan gerak pada puisi "Balerina" tampak pada baris puisi yang berbunyi "Berputar mengitari panggung/ Meliukkan tubuh dengan indah". Pada bait kedua, baris pertama dan kedua yang berbunyi " Meloncat ke sana ke mari/ bergerak dengan serasi/" juga merupakan citraan gerak yang terdapat dalam puisi tersebut.

\section{INDAH NEGERI INI}

Iska Agui Nanda Nur Awaliah

Kicauan burung terdengar merdu

Menandakan adanya hari baru

Indahnya negeri ini

Membuatku terpaku

Kupejamkan mataku sejenak

Kurentangkan tanganku sejenak

Sejuk, tenang, senang, kurasakan

Keindahan alam terasa sempurna

Membuat semua orang terpana

Tetapi, kita harus menjaganya

Agar keindahannya

Takkan pernah sirna

Dalam puisi "Indah Negeri Ini" berisi tentang penyampaian kepada pembaca bahwa negeri tempat tinggal aku lirik adalah tempat yang indah. Setiap hari ia mendengarkan kincauan burung, udara terasa sejuk dan tenang, dan pengarangpun berharap keindahan negeri tidak akan sirna. Citraan pendengaran tampak pada puisi tersebut. Hal ini terlihat pada baris yang berbunyi "Kicauan burung terdengar merdu" dengan citraan pendengaran 
itu pengarang mengajak pembaca seolah-olah mendengarkan suara burung berkicau. Citraan perabaan yang terdapat dalam puisi "Indah Negeri Ini" terlihat pada bait kedua puisi yang berbunyi "Kupejamkan mataku sejenak/ Kurentangkan tanganku sejenak/ Sejuk, tenang, senang, kurasakan". Pada kalimat tersebut kata sejuk dipilih pengarang untuk menyatakan rasa yang nyaman yang pengarang rasakan ketika menikmati indahnya negeri ini. Pada baris puisi yang berbunyi "Keindahan alam terasa sempurna/ Membuat semua orang terpana" termasuk dalamcitraan penglihatan. Pengarang menggunakan kata terpana untuk memberikan kesan seolah-olah pembaca juga melihat keindahan negeri ini. Pemanfaatan citraan-citraan tersebut dapat mendukung pengungkapan perasaan dan makna dalam puisi yang ingin disampaikan oleh pengarang.

\section{MATAHARI}

Luma'a Khoirunnisa

Matahari

Sinarmu menyinari di pagi hari

Panasmu menghangatkan tubuh ini

Kau menerangi bumi

Matahari

Bersama air kau menciptakan pelangi

Kau selalu dikelilingi bumi

Sinarmu dibutuhkan semua makhluk hidup

Luma'a Khoirunnisa dalam puisinya yang berjudul "Matahari" berisi tentang matahari yang bersinar cerah menyinari alam ini, semua makhluk hidup membutuhkan matahari. Pengarang dalam puisi itu menggunakan citraan penglihatan dan perabaan untuk membuat puisinya lebih bermakna. Citraan penglihatan tampak jelas pada kata Matahari. Kata Matahari digunakan pengarang untuk menunjukkan tema pada puisi yang ditulisnya dan membuat pembaca seolah melihat matahariyang menyinari bumi. Citraan perabaan tampak pada baris puisi yang berbunyi "Panasmu menghangatkan tubuh ini". Pembaca puisi "Matahari" seolah merasakan kehangatan dari sinar yang dipancarkan oleh matahari.

AIR
Air

Kau telah membebaskanku

dari kehausan

Air

Kau membersihkanku

dari kotoran

Air

Bila datang dalam hujan deras

Kau bisa jadi banjir

Air

Kau bisa menjadi sahabat

Juga bisa menakutkan

Puisi karya Yasmin Muthia yang berjudul "Air" bermakna tentang pentingnya air dalam kehidupan. Air memiliki fungsi penting dalam kehidupan ini, tetapi dia juga bisa merugikan apabila air menjadi banjir. Citraan yang digunakan oleh penyair untuk menimbulkan kesan pada puisi yang ditulisnya adalah citraan penglihatan dan pengecapan. Citraan penglihatan tampak jelas pada baris puisi yang berbunyi "Air bila datang dalam hujan deras/ kau bisa jadi banjir." Citraan pengecapan tampak jelas pada kata kehausan pada baris puisi yang berbunyi "Air kau telah membebaskanku dari kehausan." Kata kehausandigunakan pengarang untuk memberikan kesan bahwa pembaca ikut merasakan haus.

JAM

Zahra Anita

Beraneka rupanya

Ada bundar, kotak,

Jajaran genjang dan segitiga

Beraneka tempatnya

Di dinding dan di tangan

Semua ada, semua bisa

Menunjukkan waktu

Sesuai tugasnya

Puisi "Jam" berisi tentang pemberitahuan bahwa jam ada beraneka ragam. Citraan yang digunakan pengarang untuk memberikan kesan pada puisi yang ditulisnya adalah citraan penglihatan. Citraan penglihatan tampak pada baris puisi yang berbunyi "Beraneka rupanya/ ada bundar, kotak/ jajaran genjang dan 
segitiga". Zahra Anita hanya menggunakan citraan penglihatan dalam puisinya.

Ummu Salimah

IBU

Ibu

Terima kasih

Engkau telah melahirkan dan mendidik aku

Dan mengasuh aku dari kecil hingga besar

Aku takkan bisa membalas jasamu

yang sangat besar

engkau begitu mulia dan berarti di dunia ini

tanpamu ibu,

aku tak ada di dunia ini

jasamu sungguh sangat berarti

dan tak tergantikan

terima kasih ibu

Citraan yang terdapat dalam puisi "Ibu" karya Ummu Salimah adalah citraan penglihatan. Dalam puisi berisi tentang rasa terima kasih kepada ibunya yang telah melahirkannya. Citraan penglihatan digunakan oleh pengarang agar pembaca seolah-olah membayangkan sosok seorang ibu yang sangat berarti bagi si pengarang. Hal tersebut tampak dalam setiap bait /tanpamu ibu/ aku tak ada di dunia ini/ jasamu/ sungguh sangat berarti/dan tak tergantikan/terima kasih ibu.

\section{Simpulan}

Citraan digunakan anak-anak dalam menulis puisi untuk membangun gambaran angan atau pikiran pada pembacanya. Dengan adanya gambaran-gambaran tersebut pembaca dapat membayangkan atau merasakan hal yang diungkapkan pengarang dalam puisi anak tersebut. Citraan dapat merangsang dan mengasah daya imajinasi anak. Imajinasi tersebut kemudian dapat membuat anak lebih kreatif dalam berkarya.

Berdasarkan analisis citraan terhadap puisi anak dalam majalah Bobo edisi $40-45$ yang dijadikan data penelitian, peneliti memperoleh gambaran bahwa citraan penglihatan merupakan citraan yang paling dominan digunakan oleh anak dalam membuat puisi yang ada pada majalah Bobo edisi 40 45. Citraan yang muncul berikutnya adalah citraan gerak, kemudian citraan penciuman, citraan pencecapan, dan citraan perabaan.
Penggunaan citraan-citraan pada puisi anak dalam majalah Bobo edisi $40-45$ ini sangatlah bermanfaat untuk memberikan makna dan kesan pada isi puisi yang dibuat oleh anak-anak dalam majalah Bobo edisi $40-45$ tersebut.

\section{Daftar Pustaka}

Husna, Iswani. 2017. Analisis Citraan Puisi Anak Majalah Bobo: Fakultas FKIP Universitas.Etd. Unsiyah. ac.id. 28 Juli 2017.

Majalah Bobo. 2016. Taman Bunga, Melatiku, Rumahku. Jakarta: Kelompok Kompas Gramedia.

Majalah Bobo. 2016. Air, Jam, Ibu. Jakarta: Kelompok Kompas Gramedia.

Majalah Bobo. 2016. Burung Berbulu Putih, Pelangi, Bundaku. Jakarta: Kelompok Kompas Gramedia.

Majalah Bobo. 2016. Paru-paru Dunia, Balerina, Indahnya Negeri ini. Jakarta: Kelompok Kompas Gramedia.

Majalah Bobo. 2016. Tas Baru, Bunga Mawar Merah. Jakarta: Kelompok Kompas Gramedia.

Majalah Bobo. 2016. Indahnya Negeri ini. Jakarta: Kelompok Kompas Gramedia

Nurgiantoro, Burhan. 2005. Sastra Anak. Yogyakarta: Gadjah Mada University Press.

Pradopo, Rachmat Djoko. 2010. Pengkajian Puisi. Yogyakarta: Gadjah MadaUniversity Press.

Ratna, Nyoman Kutha. 2004. Teori, Metode, dan Teknik Penelitian Sastra.Yogyakarta: Pustaka Pelajar.

Sarumpaet. Riris K. Toha. 2010. Pedoman Penelitian Sastra Anak. Jakarta: PusatBahasaKementerian Pendidikan Nasional.

Tarigan, Henry Guntur. 2011. Dasar-dasar Psikosastra. Bandung: Angkasa.

Waluyo, Herman J. 1991. Teori dan Apresiasi Puisi. Jakarta: Erlangga.

Winarni, Retno. 2014. Kajian Sastra Anak Edisi 2. Yogyakarta: Graha Ilmu. 